\title{
Direct interaction between DNMT1 and G9a coordinates DNA and histone methylation during replication
}

\author{
Pierre-Olivier Estève, ${ }^{1}$ Hang Gyeong Chin, ${ }^{1}$ Andrea Smallwood, ${ }^{2}$ George R. Feehery, ${ }^{1}$ \\ Omkaram Gangisetty, ${ }^{3}$ Adam R. Karpf, ${ }^{3}$ Michael F. Carey, ${ }^{2}$ and Sriharsa Pradhan ${ }^{1,4}$ \\ ${ }^{1}$ New England Biolabs, Ipswich, Massachusetts 01938, USA; ${ }^{2}$ Department of Biological Chemistry, Gene Regulation \\ Program, Jonsson Cancer Center, University of California at Los Angeles School of Medicine, Los Angeles, California 90095, \\ USA; ${ }^{3}$ Department of Pharmacology and Therapeutics, Roswell Park Cancer Institute, Buffalo, New York 14263, USA
}

\begin{abstract}
Chromatin methylation is necessary for stable repression of gene expression during mammalian development. During cell division, DNMT1 maintains the DNA methylation pattern of the newly synthesized daughter strand, while G9a methylates H3K9. Here, DNMT1 is shown to directly bind G9a both in vivo and in vitro and to colocalize in the nucleus during DNA replication. The complex of DNMT1 and G9a colocalizes with dimethylated H3K9 (H3K9me2) at replication foci. Similarly, another H3K9 histone methyltransferase, SUV39H1, colocalizes with DNMT1 on heterochromatic regions of the nucleoli exclusively before cell division. Both DNMT1 and G9a are loaded onto the chromatin simultaneously in a ternary complex with loading factor PCNA during chromatin replication. Small interfering RNA (siRNA) knockdown of DNMT1 impairs DNA methylation, G9a loading, and H3K9 methylation on chromatin and rDNA repeats, confirming DNMT1 as the primary loading factor. Additionally, the complex of DNMT1 and G9a led to enhanced DNA and histone methylation of in vitro assembled chromatin substrates. Thus, direct cooperation between DNMT1 and G9a provides a mechanism of coordinated DNA and H3K9 methylation during cell division.
\end{abstract}

[Keywords: DNMT1; G9a; SUV39H1; methylation; chromatin; replication]

Supplemental material is available at http://www.genesdev.org.

Received June 27, 2006; revised version accepted September 29, 2006.

Epigenetic information, encoded into the chromatin by virtue of covalently modified DNA and histone molecules (Holliday 1994; Turner 2000) provides a hereditable mechanism to regulate and maintain gene expression patterns through DNA replication. The basic unit of chromatin, the nucleosomes, consists of 147 base pairs (bp) of double-stranded DNA wrapped around two copies of core histones $\mathrm{H} 2 \mathrm{~A}, \mathrm{H} 2 \mathrm{~B}, \mathrm{H} 3$, and $\mathrm{H} 4$ (Luger et al. 1997). Adjacent nucleosomes can fold into higher order structures that can restrict the accessibility of various basal and specific transcription factors or enzymes. During cell division and DNA replication, maintenance of the DNA methylation pattern onto the daughter strand is essential for stable repression of genes. In the G1 and G2 phases of the cell cycle, DNMT1 remains diffused throughout the nucleoplasm, but associates with replication foci during S phase (Leonhardt et al. 1992; Liu et al. 1998). Movement of the replication machinery transiently disrupts the chromatin fiber and leads to the random segregation of the parental nucleosomes among the

${ }^{4}$ Corresponding author.

E-MAIL pradhan@neb.com; FAX (978) 921-1350.

Article published online ahead of print. Article and publication date are online at http://www.genesdev.org/cgi/doi/10.1101/gad.1463706. two daughter strands (Gruss and Sogo 1992). Additional nucleosomes are added onto the newly synthesized DNA via deposition of newly synthesized histone $(\mathrm{H} 3 / \mathrm{H} 4)_{2}$ tetramers followed by H2A/H2B dimers (Jackson 1990; Gruss et al. 1993). Furthermore, the new nucleosomes contain acetylated histone $\mathrm{H} 4$ and $\mathrm{H} 3$, which is a prerequisite for nuclear transport (Mosammaparast et al. 2002). Thus, nucleosomes in the newly synthesized DNA are expected to contain new acetylation but lack other chromatin-specific epigenetic marks such as methylation. To re-establish the original epigenetic marks, the new histones must undergo removal of some modifications while allowing other modifications to occur. Indeed, acetyl groups on new histones are rapidly removed in mammalian cells (Taddei et al. 1999), perhaps allowing the patterns of modification existing prior to replication to be re-established. Although the core regions of the histone octamer remain inside the nucleosome, the N-terminal tails are exposed, and thus are amenable to events such as methylation, acetylation, phosphorylation, sumoylation, ADP-ribosylation, and ubiquitination (Van Holde 1988; Wolffe 1998).

The $\mathrm{N}$-terminal regions of histones $\mathrm{H} 3$ and $\mathrm{H} 4$ are highly modified. Lysine residues at positions 4, 9, 27, and 
36 of histone $\mathrm{H} 3$ and 20 of histone $\mathrm{H} 4$ are methylated (Lachner et al. 2003). Methylation of Lys 9 of histone H3 (H3K9) has been extensively studied and shown to correlate with transcriptional gene silencing. Furthermore, the methylation of lysines on histones is reversible and shown to regulate gene expression (Wysocka et al. 2005). The methylated H3K9 serves as a specific binding site for heterochromatin protein 1 (HP1). The Suv39h class of enzymes maintains methylation of heterochromatin (Rea et al. 2000), while in mammals G9a is likely to be the major euchromatic H3K9 histone methyltransferase. Gene disruption of G9a in mice significantly decreases H3K9 methylation in euchromatic regions (Tachibana et al. 2002). Using a panel of antibodies specific for mono-, di-, and trimethylated H3K9 with G9a-null embryonic stem cells or Suv39h1 and Suv39h2 double-null mouse embryonic fibroblast cells, it was established that G9a is specific for mono- and dimethylation, whereas Suv39h1 and Suv39h2 are largely responsible for trimethylation (Rice et al. 2003). However, recent biochemical studies with purified full-length G9a or its SET domain, along with a substrate peptide bearing the $\mathrm{N}$ terminus of histone $\mathrm{H} 3$, suggest that G9a is capable of mono-, di-, and trimethylation of Lys 9, although the transition from dito trimethylation is rate limiting (Patnaik et al. 2004; Collins et al. 2005). G9a-null mice display severe growth retardation and die between embryonic days 9.5 and 12.5 due to deregulation of developmental genes (Tachibana et al. 2002). Thus, G9a deficiency is not complemented by other known H3K9 methyltransferases. A similar growth retardation and embryonic lethality was observed in DNMT1-null mice (Li et al. 1992). These observations support a direct link between epigenetic gene regulation and mammalian development.

DNA replication in eukaryotic cells stimulates a complex array of responses (Stillman 2005). During DNA replication, DNMT1 is loaded onto replication fork via PCNA (Chuang et al. 1997) and participates in methylation of CpG sites (Leonhardt et al. 1992). Histone methyltransferase-mediated DNA methylation is demonstrated for EZH2 target promoters (Vire et al. 2006), IAP elements, and Mage genes (Dodge et al. 2004; Tachibana et al. 2002). In a previous study, we demonstrated that doxorubicin-induced repression of the anti-apoptotic survivin gene is caused by DNA and histone methylation of its proximal promoter, which is mediated by the physical recruitment of DNMT1 (Estève et al. 2005a). However, the mechanism underlying coordinated DNA and histone methylation during DNA replication has not been previously reported. In this report, we demonstrate a physical association and functional cooperation between two epigenetic factors, DNMT1 and G9a, during DNA synthesis.

\section{Results}

Interaction between maintenance DNMT1 and G9a in vivo

The observation that DNA and histone methylation on euchromatic regions is carefully preserved during repli- cation raised the possibility that the histone and DNA methyltransferases engage in direct cross-talk. To determine whether DNMT1 associates with G9a in cells, we cotransfected a GFP-G9a fusion construct along with 6xHis-tagged DNMT1 into COS-7 cells. After 48 h, we immunoprecipitated protein complexes from cell extracts using anti-GFP and anti-DNMT1 antibodies. The GFP and DNMT1 antibodies both precipitated GFP-G9a (Fig. 1A, lanes 2,3, top and middle), and DNMT1 (Fig. 1A, lanes 2,3, top and bottom). Precipitation of DNMT1 required G9a, as cotransfection of the GFP empty vector along with the DNMT1 construct did not yield a detectable complex formation (Fig. 1A, lane 1). In a similar experiment, we were also able to coimmunoprecipitate endogenous DNMT1 and G9a from HCT116, but not in DNMT1-null HCT116 cells (Fig. 1B). Endogenous coimmunoprecipitation of DNMT1 and G9a was also observed in HEK293 cells (data not shown). We further verified the existence of DNMT1 and G9a in the same complex by gel filtration chromatographic separation of Jurkat cell nuclear extract. The estimated molecular mass of DNMT1 and G9a are 183 and $140 \mathrm{kDa}$, respectively. A complex between DNMT1 and G9a would result in a combined mass $>320 \mathrm{kDa}$, thus the complex can be resolved from DNMT1 or G9a monomer and be detected by Western blot analysis. Indeed, the chromatographic peak containing DNMT1, G9a, and H3K9me2 eluted approximately at a molecular mass of $449 \mathrm{kDa}$ (Fig. 1C) as determined by gel filtration elution of the standard protein. All of the G9a was in complex with DNMT1 since no G9a protein was detected eluting at the region of the $158-\mathrm{kDa}$ protein standard. To further validate this observation, we performed immunoprecipitation of DNMT1 and G9a using anti-DNMT1 or anti-G9a antibodies. A microgram of anti-DNMT1 captured some DNMT1, but all of the G9a. The unbound fraction of the nuclear extract did not display the presence of free G9a. When a microgram of anti-G9a was used for immunoprecipitation, all of the G9a was captured, but only a fraction of DNMT1 was found in the captured complex (Fig. 1D). A nonspecific anti-GFP antibody did not immunoprecipitate either G9a or DNMT1 (data not shown). We conclude from these experiments that DNMT1 and G9a exist in a stable complex in vivo and almost all of the G9a is in the form of a complex with DNMT1. However, it remained possible that the association was mediated by other proteins that bridged the interaction.

To determine whether DNMT1 directly interacts with G9a we used pull-down assays using purified proteins. Fragments of G9a encompassing the entire 1263-aminoacid protein were fused to GST and purified on glutathione beads. The bead-bound GST fusion proteins were incubated with purified recombinant full-length DNMT1 (purified using a baculovirus expression system) (Pradhan et al. 1999). The N-terminal region of G9a encompassing the first 463 amino acids bound tightly to DNMT1, whereas a deletion bearing amino acids 291-633 did not (Fig. 1E). When the GST-G9a full-length and DNMT1 fulllength enzymes were incubated together, DNMT1 re- 
A
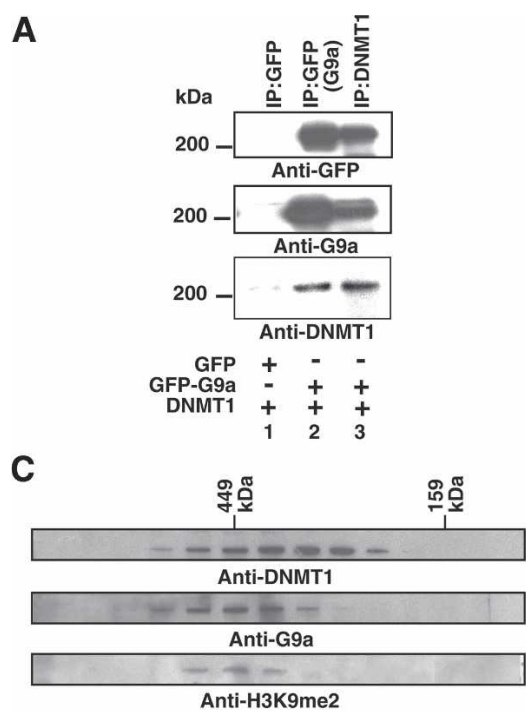

F
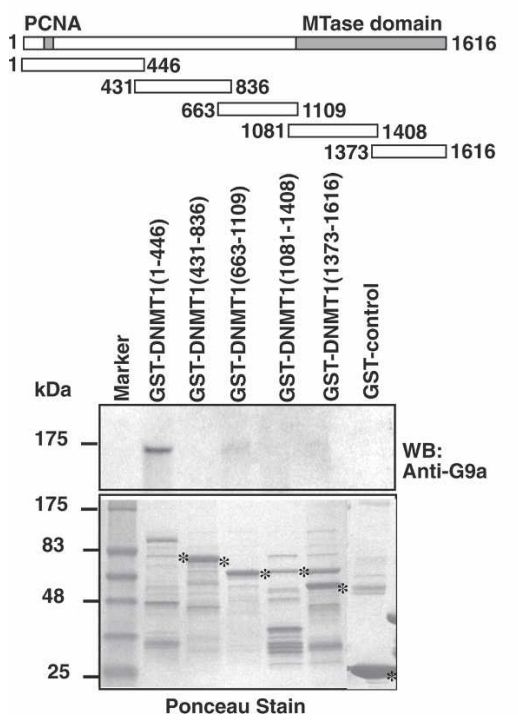

B

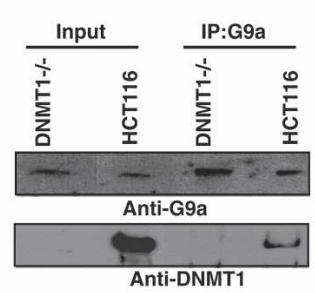

D

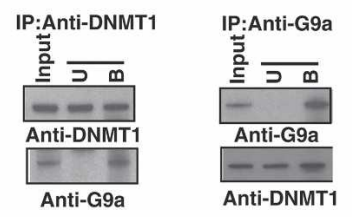

E

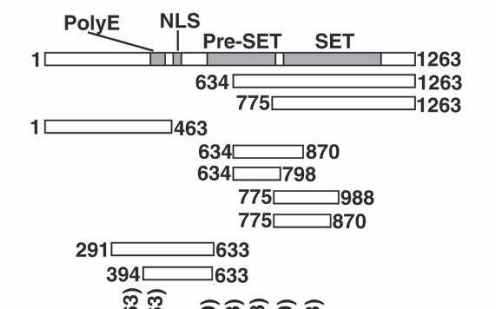

Figure 1. Interaction between DNMT1 and G9a. (A) Coimmunoprecipitation of DNMT1 and G9a in cell extracts from COS-7 cells transfected with GFP-G9a and 6xHis-DNMT1 constructs. The antibodies used for immunoprecipitation are indicated at the top and the molecular weight marker at the left. Each blot was probed with antibody as indicated. $(B)$ Coimmunoprecipitation of endogenous DNMT1 and G9a in human HCT116 cells. The input nuclear extracts and immunoprecipitated antibody used are shown. Antibodies used for Western blot are indicated below each panel. $(C)$ Chromatographic separation of DNMT1 and G9a complexes. Elution profile of the gel filtration standard proteins in kilodaltons is indicated at the top and antibodies used for detection of enzymes in various fractions are shown at the bottom. All three blots were against the same elution fractions. $(D)$ Coimmunoprecipitation of endogenous DNMT1 and G9a in human Jurkat cells. The input ( $8 \%$ for DNMT1 and 50\% for G9a) and antibodies used for immunoprecipitation are shown at the top. Antibodies used for Western blot are indicated below each panel. The unbound (U) and bound (B) G9a and DNMT1 are shown. Typically, $1 \mu \mathrm{g}$ of antibodies was used for IP. Note that all G9a were immunoprecipitated by antiG9a, as the unbound fraction did not contain any detectable amount of G9a. (E) Mapping of the DNMT1-binding region on G9a using GST fusions of G9a fragments. Various domains of G9a are indicated above the panels along with a schematic presentation of the GST fusion constructs. Ponceau-stained transferred proteins from GST pull-down experiments are shown along with the Western blot using antiDNMT1. Positions of the fusion proteins are marked with asterisks. Amino acids in the fusion proteins are indicated in parenthesis at the top of the blot. (F) Schematic diagram depicting GST fusion constructs using various regions of DNMT1 along with amino acid numbers. Ponceau-stained transferred proteins from GST pull-down experiments are shown along with the Western blot of it with anti-G9a.

mained bound to G9a (Fig. 1E). A reciprocal GST pulldown assay was performed using GST fusion fragments of DNMT1 encompassing the entire 1616-amino-acid enzyme and recombinant full-length G9a. G9a bound to a region of DNMT1 containing the first 446 amino acids (Fig. $1 F)$. These data suggest that DNMT1 and G9a directly interact and that the $\mathrm{N}$ termini of DNMT1 and G9a mediate this interaction. To unequivocally demonstrate the binding between the N-terminal region of DNMT1 and G9a, additional in vitro binding assays were performed. We incubated the full-length DNMT1 with either a full-length G9a or an N-terminal deletion MBP fusion mutant lacking the first 633 amino acids (MBP-delG9a), the putative DNMT1-binding motif. The incubation mixture was subjected to immunoprecipitation using either anti-DNMT1,
anti-G9a, or anti-MBP antibodies and examined for the presence of both G9a and DNMT1 by Western blot analysis. Indeed, a strong complex between DNMT1 and G9a full-length proteins was observed (Supplementary Fig. 1, lanes 1,3$)$ and this binding was disrupted in the presence of MBP-delG9a (Supplementary Fig. 1, lanes 2,4).

The physical interaction of DNMT1 and euchromatic histone methyltransferase G9a (Tachibana et al. 2002) represents a potential mechanism by which DNA and histone methylation could be coordinated on euchromatic regions in vivo during replication. One prediction of this idea is that G9a and DNMT1 should colocalize at replication foci during DNA replication in early $S$ phase, when the bulk of the euchromatic region of the genome undergoes replication (Gilbert 2002). 
Colocalization of DNMT1 and G9a during DNA replication and their association with methylated $H 3 \mathrm{~K} 9$

DNMT1 associates with replication foci during DNA replication via direct interaction with PCNA, a replication processivity factor (Chuang et al. 1997). Our findings that DNMT1 interacts with G9a suggested the possibility that DNMT1 recruits G9a to active sites of replication. To address the functional significance of the complex of DNMT1 and G9a and to understand the sequence of events occurring during replication, we cotransfected a GFP-G9a fusion along with a DsRedDNMT1 fusion construct into either HeLa or COS-7 cells. The cells were synchronized with aphidicolin at the G1/S border and visualized for the localization of the fusions in the nuclei by fluorescence microscopy. The quality of the synchronization at different time points was monitored by bromodeoxyuridine (BrdU) (pulse chase) incorporation, immunostaining, and scoring for BrdU-incorporated cells. At the $2-4 \mathrm{~h}$ time point, $\sim 90 \%$ of the cells displayed BrdU incorporation. The percentage of BrdU-incorporated cells increased to $98 \%$ by the eighth hour. The replication foci, as revealed by BrdU incorporation, appeared from small spotty clusters to large red punctate nuclear spots as the replication time progressed (Supplementary Fig. 2). In the colocalization studies, distinctive green spots appeared in the nuclei of the cells transfected with the GFP-G9a fusion construct. A similar pattern of red punctate nuclear spots was observed in cotransfected cells, revealing that DNMT1 is localized in the nucleus (Fig. 2A), as observed previously (Leonhardt et al. 1992). Superimposition of GFP-G9a and DsRed-DNMT1 resulted in yellow nuclear spots throughout the nucleus, excluding the nucleolus, which remained dark (Fig. 2A, panels II,III). The yellow merged patterns between DNMT1 and G9a fusions were observed throughout $S$ phase $(2-15 \mathrm{~h}$ after aphidicolin treatment) in the majority of double transfectants (Fig. 2A). Cells displaying this pattern during the first $4 \mathrm{~h}$ (Fig. 2A, panel II) also had prominent nucleoli, a sign of early S phase. The DNMT1-G9a complexes were toroidal shaped at the replication foci during late $S$ phase $(8-15 \mathrm{~h}$ post-synchronization, Fig. 2A, panels III,IV) as observed before for colocalization of DNMT1 and its associated protein, DMAP1 (Rountree et al. 2000). The relevance of the colocalization during replication was further highlighted by the observation that during metaphase both DNMT1 and G9a were excluded from condensed chromatin (data not shown).

To confirm that the N termini of G9a and DNMT1 interact with each other, a GFP fusion construct containing the first 446 amino acids of DNMT1 GFP-DNMT1 (1-446) was cotransfected with DsRed-G9a full-length fusion (DsRed-G9a) (Fig. 2B) into synchronized cells. Once again, distinctive green spots appeared in the nuclei of the cells transfected with the GFP-DNMT1 (1446) fusion and a similar pattern of red punctate nuclear spots was observed with DsRed-G9a. Superimposition of GFP-DNMT1 (1-446) and DsRed-G9afl resulted in yellow nuclear spots throughout the nucleus, excluding the nucleolus, which remained dark (Fig. 2B). Similarly, a DsRed fusion construct containing the first 502 amino acids of DNMT1 was cotransfected with a GFP fusion of G9a containing the first 464 or 598 amino acids. We observed yellow spots in the DNMT1-G9a merged panels (Fig. 2C,D) similar to Figure 2A, panels II and III, demonstrating the colocalization of the $\mathrm{N}$ terminus of both DNMT1 and G9a. Thus, the cumulative results from GST pull-down analysis (Fig. 1E,F) and colocalization studies between DNMT1 and G9a confirm recruitment of both epigenetic factors.

To validate that G9a and DNMT1 colocalize at active sites of DNA synthesis, transfected cells were pulsechased with BrdU. BrdU becomes incorporated into newly synthesized DNA, thus macromolecules at the vicinity of newly synthesized DNA may be colocalized along with the BrdU signal. Previous studies showed that DNMT1 colocalized with BrdU in cycling cells (Leonhardt et al. 1992). Thus, we initially examined whether G9a would also colocalize with BrdU. As shown in Figure $2 \mathrm{E}$, the yellow punctate pattern indicates that GFPG9a was almost exclusively colocalized with BrdU (red) in the replicating nuclear DNA. A parallel experiment with GFP-DNMT1 and BrdU displayed a similar pattern of colocalization as observed previously (Fig. 2F; Leonhardt et al. 1992). The data of Figure 2A showing G9a and DNMT1 colocalization, coupled with the data of Figure 2, E and F, provide strong support for the idea that G9a and DNMT1 localize close to sites of DNA synthesis.

If DNMT1 recruits G9a to the chromatin and the interaction is indeed functional, there should be a correlation between the DNMT1-G9a association and histone methylation. We addressed this hypothesis via two sets of immunocytochemistry experiments. In the first set, cells were transfected with the GFP-G9a fusion construct and probed with $\mathrm{H} 3 \mathrm{~K} 9 \mathrm{me}$-specific antibodies (Fig. 2G). In the second set, cells were transfected with the DsRed-DNMT1 fusion construct and probed with H3K9me2-specific antibodies (Fig. 2H). The majority of H3K9me2 was in close proximity to G9a (Fig. 2G) and DNMT1 (Fig. 2H) as evidenced by a similar punctate colocalization pattern. Thus, DNMT1, G9a, and H3K9me2 are present in the vicinity of DNA synthesis during cell division.

Association and interaction between DNMT1 and SUV39H1 occurs on pericentric heterochromatin before DNA replication

Mammalian heterochromatin is enriched with H3K9me3, the catalytic product of the Suv39h1 class of histone methyltransferases (Lehnertz et al. 2003). Genetic deletion of Suv39h1, a mouse homolog of human SUV39H1, resulted in reduction of $\mathrm{H} 3 \mathrm{~K} 9 \mathrm{me} 3$, but not mono or $\mathrm{H} 3 \mathrm{~K} 9 \mathrm{me} 2$, confirming its catalytic role in trimethylation (Lehnertz et al. 2003; Rice et al. 2003). Furthermore, genetic deletion of G9a resulted in drastic reduction of mono and $\mathrm{H} 3 \mathrm{~K} 9 \mathrm{me} 2$, suggesting that G9a maintains some mono and the majority of H3K9me2 (Peters et al. 2003; Rice et al. 2003). Additionally, Suv39h1 and H3K9me3 colocalize on hetero- 
Downloaded from genesdev.cshlp.org on April 26, 2023 - Published by Cold Spring Harbor Laboratory Press

DNMT1 and G9a coordinate chromatin methylation

\section{A}

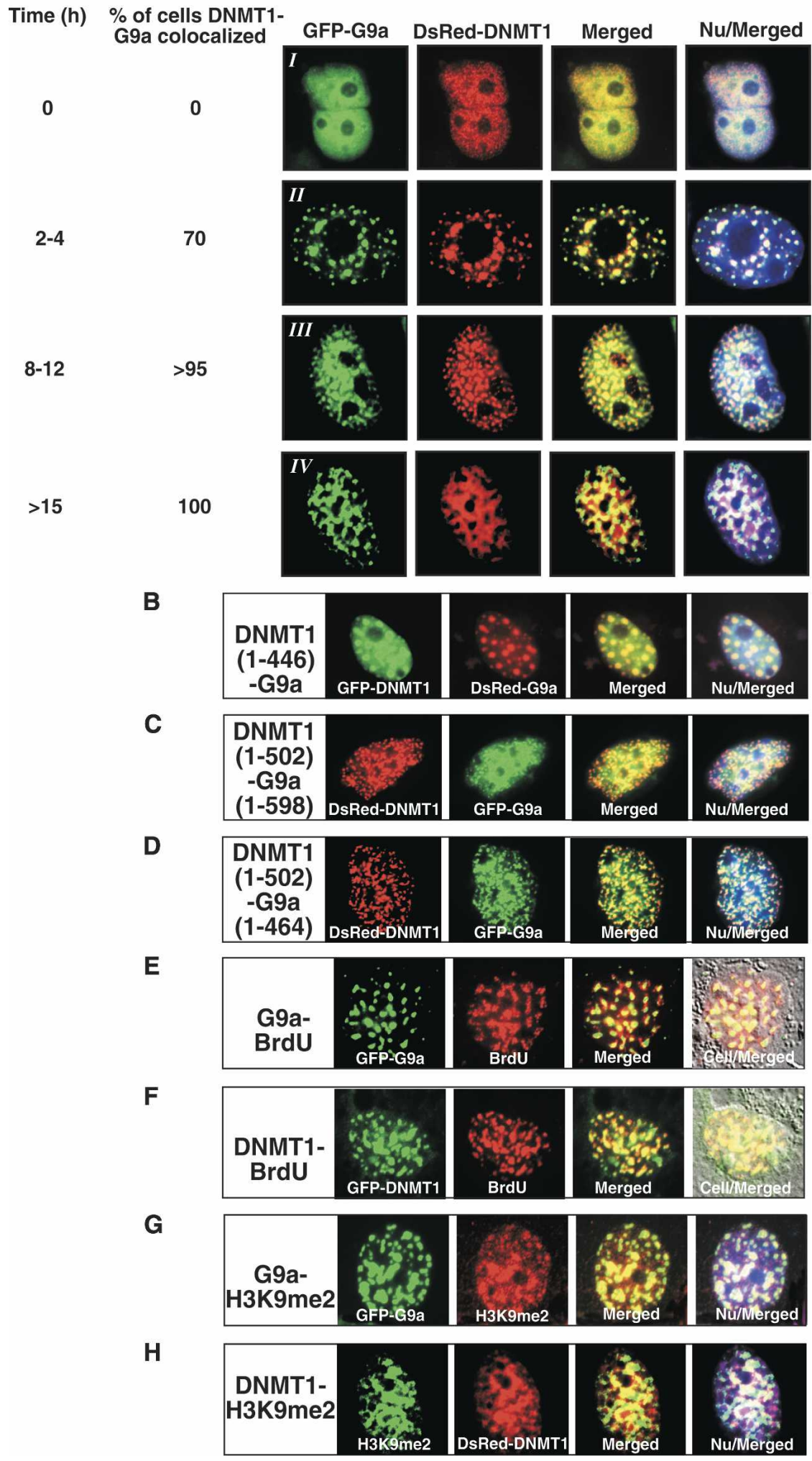

Figure 2. Colocalization of G9a and DNMT1 at the replication foci along with BrdU and H3K9me2 localization with either DNMT1 or G9a. Fusion proteins are shown at the top of the panels along with immunocytochemical detection of BrdU or H3K9me2 as indicated. Panels are designated $A-H$. In the left-hand corner of $B-H$, the identity of the fusion proteins and the antibody used for immunocytochemistry is noted. $(\mathrm{Nu})$ nucleus stained by hoechst staining; (BrdU) bromodeoxyuridine; (H3K9me2) dimethylated histone H3 Lys 9. The DNMT1 and G9a fusion constructs used are either fused with DsRed (DsRed-DNMT1) or GFP (GFPDNMT1). A fusion protein containing either a GFP or DsRed partner along with a portion of G9a or DNMT1 as indicated in bracket is used. (A) G9a and DNMT1 colocalization during cell cycle. On the left side of the panel, cytochemical observation after synchronization in hours and percent of cells where DNMT1 and G9a fusions are colocalized are given. For each stage (at 0 time [panel $I$ ], between 2 and 4 $\mathrm{h}$ [panel $I I]$, between 8 and $12 \mathrm{~h}$ [panel $I I I]$, and after $15 \mathrm{~h}$ [panel $I V]$ post-aphidicolin treatment), 20-50 cells were counted. $(B)$ DNMT1 (1-446) and G9a. (C) DNMT1 (1502) and G9a (1-598). (D) DNMT1 (1-502) and G9a (1-464). (E) G9a and BrdU. (F) DNMT1 and BrdU. (G) H3K9me2 and G9a. (H) DNMT1 and H3K9me2. Amino acids numbers are in parentheses.

chromatin (Fig. 3A; Peters et al. 2001) as was observed for DNMT1 and H3K9me3 (Fig. 3B). To understand the physical relationship between DNMT1 and SUV39H1, GST fu- sion fragments of DNMT1 covering the whole enzyme were incubated with purified full-length recombinant SUV39H1 in a GST pull-down assay. The bound proteins 

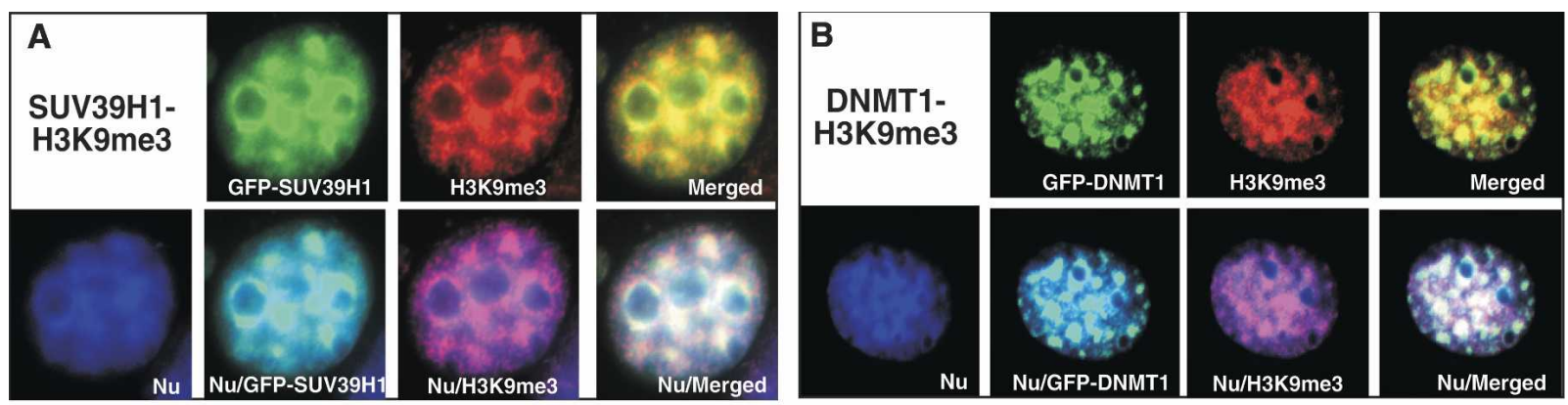

C

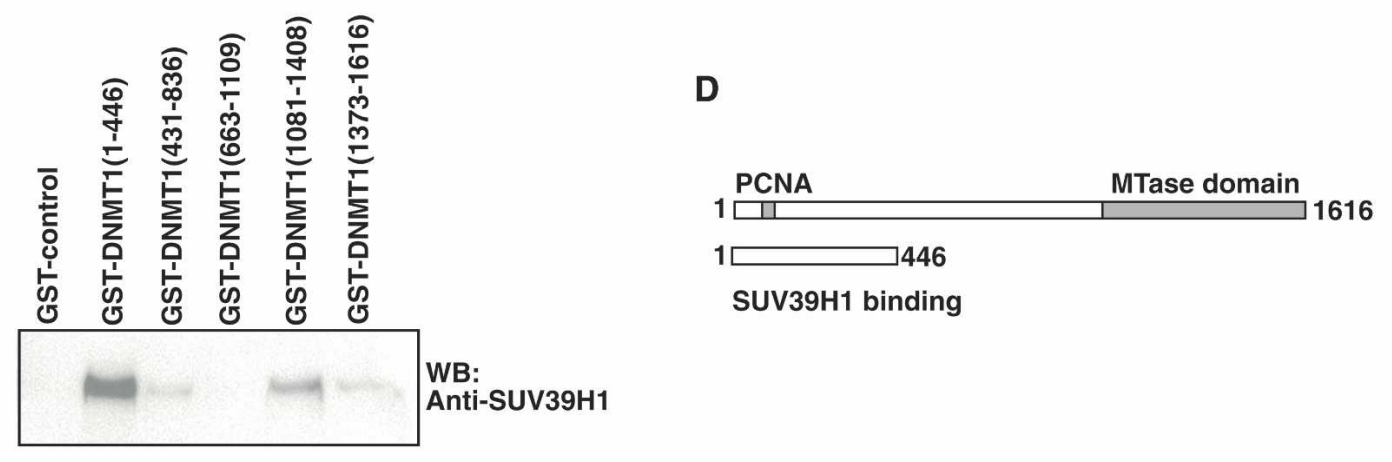

E

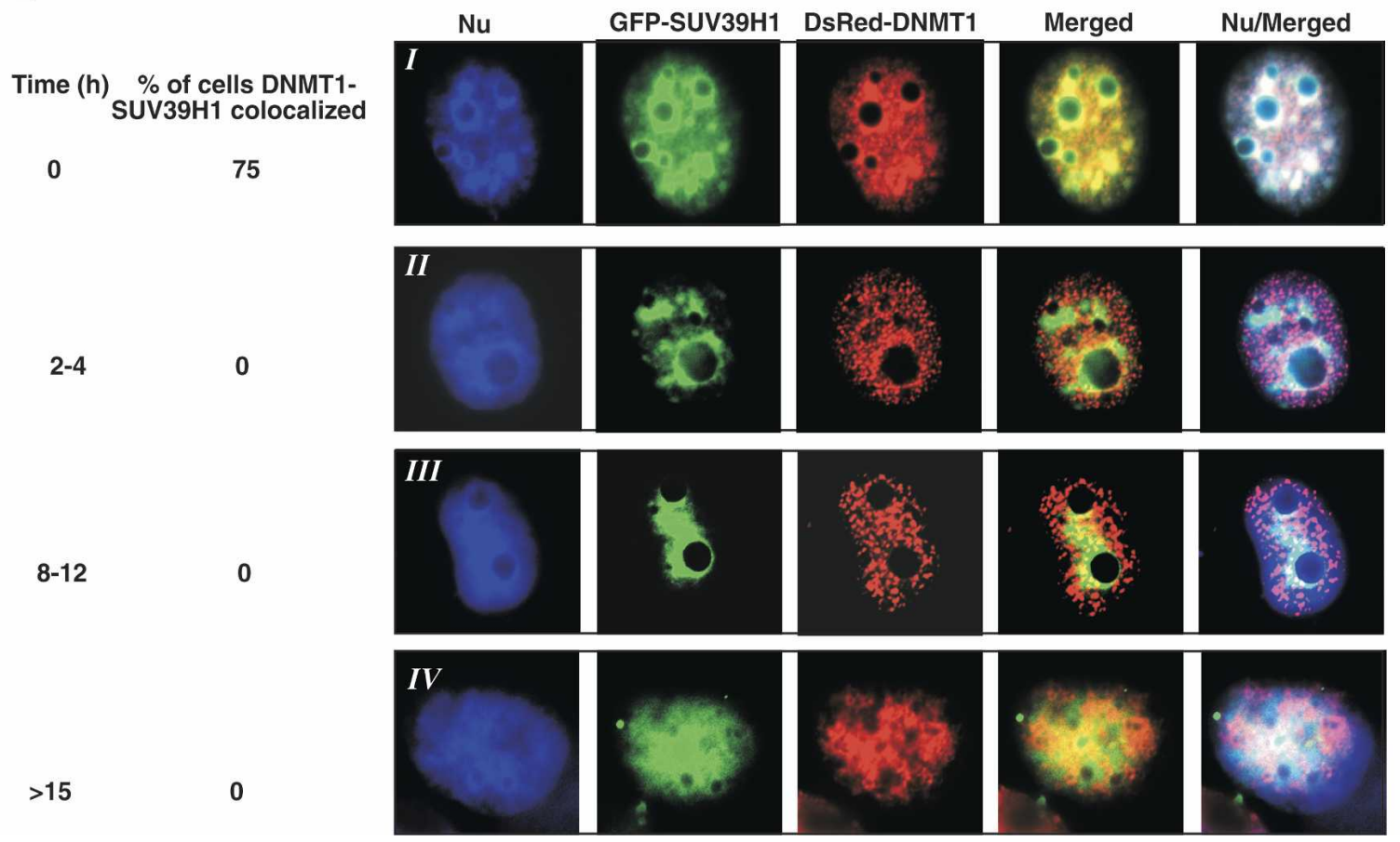

Figure 3. Colocalization and interaction between DNMT1 and SUV39H1. (A) Cytochemical localization of SUV39H1 and H3K9me3 in heterochromatin. (B) Cytochemical localization of DNMT1 and H3K9me3 in heterochromatin. (C) Mapping of the SUV39H1binding region on DNMT1 using overlapping GST fusion fragments of DNMT1. Various GST fusions of DNMT1 are indicated above with amino acids in parentheses and antibody used shown at right. (D) Schematic diagram of DNMT1 with SUV39H1-binding region on it shown below. (E) SUV39H1 and DNMT1 do not colocalize during DNA replication, but are associated in heterochromatin. On the left side of the panel cytochemical observation after synchronization in hours and percent of cells where DNMT1 and SUV39H1 fusions are colocalized are given. For each stage (at 0 time [panel $I$ ], between 2 and $4 \mathrm{~h}$ [panel $I I$ ], between 8 and $12 \mathrm{~h}$ [panel $I I I]$, and after $15 \mathrm{~h}$ [panel $I V]$ post-aphidicolin treatment), 20-50 cells were counted. 
were blotted and probed with anti-SUV39H1. The first 446 amino acids of DNMT1 strongly associated with SUV39H1 (Fig. 3C,D). A similar association between DNMT1 and SUV39H1 was observed previously and the complex was catalytically competent (Fuks et al. 2003).

To elucidate whether DNMT1 and SUV39H1 are associated during DNA replication, additional colocalization experiments using GFP-SUV39H1 and DsRedDNMT1 fusion constructs were performed in synchronized HeLa cells. Fluorescent localization revealed that, indeed, both DNMT1 and SUV39H1 are colocalized in the vicinity of heterochromatin and pericentric heterochromatin regions of $75 \%$ of the cells, as observed by the yellow merged pattern around the nucleolus that was densely stained by the nuclear staining (Fig. 3E, panel I). However, during DNA replication, when DNMT1 is located at the replication foci and visualized as the red punctate spots, SUV39H1 did not colocalized with it (Fig. 3E, panels II,III,IV). This observation was confirmed by a BrdU pulse-chase experiment, where SUV39H1 did not colocalize with BrdU at the replication forks although SUV39H1 appeared throughout the chromatin (data not shown). In a control immunocytochemical experiment, SUV39H1 and H3K9me3 were colocalized on the heterochromatin as was observed in Figure 3A. Exclusion of SUV39H1 from the replication foci and colocalization of it on heterochromatin with DNMT1 suggests a role for these enzymes in post-replicative H3K9 trimethylation and DNA methylation. This hypothesis gains further support by the presence of a chromodomain on SUV39H1 that can bind dimethylated H3K9 tails with high affinity (Jacobs et al. 2004). Perhaps this chromodomain-mediated anchoring of SUV39H1-dimethylated H3K9 facilitates H3K9 trimethylation as proposed earlier (Peters et al. 2003; Rice et al. 2003). Furthermore, mutation of the SUV39H1 chromodomain was shown to render the enzyme catalytically inactive (Chin et al. 2006). It is also plausible that the SUV39H1-DNMT1 binary complex may remain bound to methylated H3K9 and recruit a methylation-independent chromatin repressor complex onto the heterochromatin.

\section{Molecular mechanisms of DNMT1 and G9a cooperation}

To validate the cytochemical colocalization of DNMT1 and G9a at the vicinity of replication foci and to understand the events associated with replication-dependent chromatin methylation, we examined the connection between DNMT1-G9a loading and Lys 9 dimethylation of H3. HeLa cells were synchronized by thymidine and aphidicolin and at different time points, cells were harvested, and chromatin fractions were Western blotted to determine whether DNMT1 and G9a were loaded onto the chromatin. Indeed, the chromatin fractions displayed a gradual increase in G9a and DNMT1 in a time-dependent manner corresponding with increased amounts of H3K9me2. Significantly, the loading control H3 and SUV39H1 remained very similar in all of the time points (Fig. 4A). We further immunoprecipitated the synchro- nized cells with anti-PCNA antibodies to find out whether the docking of DNMT1-G9a binary complex is mediated by PCNA. We observed a gradual increase in DNMT1-G9a loading with a normalized PCNA level, suggesting that more DNMT1-G9a binary complexes are being formed as replication progresses (Fig. 4B). This suggests a possible formation of a trimeric complex during DNA replication. As replication proceeds, the loading and increase in PCNA-DNMT1-G9a trimeric complexes in the nucleus (Fig. 4B) is observed, demonstrating a constant supply of active enzyme complexes to the replication site. To validate the role of DNMT1 in maintaining G9a-mediated H3K9 methylation, small interfering RNA (siRNA)-mediated knockdown of the endogenous DNMT1 or G9a were performed in HeLa cells and total cellular extracts and chromatin fractions were examined for H3K9me2 changes. Knockdown of G9a resulted in $\sim 65 \%$ reduction of H3K9me2 in both total extract and chromatin fraction as compared with the control knockdown without impairment of DNMT1 loading on the chromatin (Fig. 4C, top). Moreover, DNMT1 knockdown resulted in $\sim 50 \%$ reduction of $\mathrm{H} 3 \mathrm{~K} 9 \mathrm{me} 2$ and correlated with a decrease in G9a loading onto the chromatin (Fig. 4C, right). These results indicate that knockdown of either G9a or DNMT1 results in impairment of total H3K9 methylation. A similar decrease in H3K9 diand trimethylation was observed previously in DNMT1null HCT116 cells (Espada et al. 2004).

To validate whether the impaired H3K9 methylation in DNMT1 knockdown cells is due to poor loading of G9a onto the replicating chromatin, we examined and compared the pattern of GFP-G9a and BrdU incorporation in siRNA-mediated DNMT1 knockdown COS-7 cells and DNMT1-null HCT116 cells. BrdU incorporation in both DNMT1 knockdown or DNMT1-null cells appeared throughout the nucleus, as did G9a (Fig. 4D,E). However, the majority of G9a did not colocalize with BrdU (Fig. 4D,E, merged). Therefore, these observations suggest that DNMT1 participates in localization and loading of G9a onto chromatin during DNA replication.

\section{Chromatin methylation coordinated by DNMT1 and G9a}

To demonstrate that DNMT1-G9a indeed coordinates chromatin methylation during DNA replication on specific gene sequences, we investigated the intergenic spacer (IGS) elements of rDNA. The IGS-rDNA contained six CpG dinucleotides in a span of 78 nucleotides (nt) that are a potential target for DNMTs. Recent studies indicate that an epigenetic network mediates the transcriptional state of rDNA and DNA methylation plays a major role in rDNA silencing (Santoro and Grummt 2001; Santoro et al. 2002). To establish whether IGS of rDNA is methylated and that DNMT1 is responsible for IGS-rDNA methylation, methylation-sensitive PCR (MSP) was performed on the siRNA-mediated DNMT1 knockdown genome or on cells treated with zebularine, a DNMT1-specific mechanistic inhibitor (Karpf and Jones 2002; Cheng et al. 2004). MSP can dis- 
A

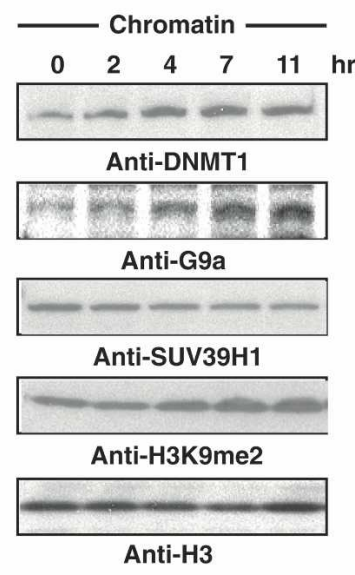

C

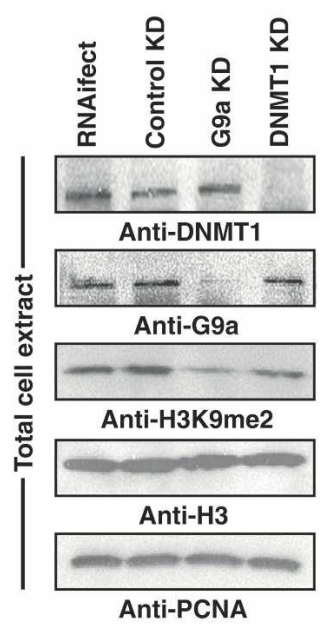

B

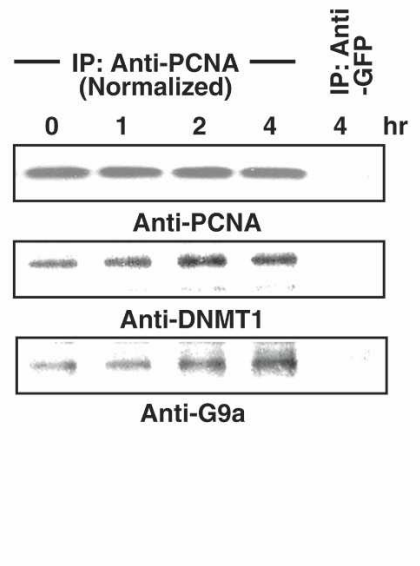

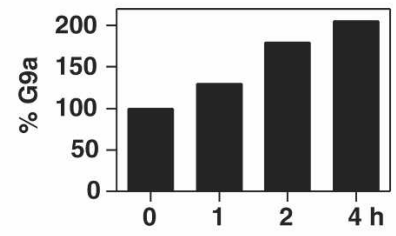
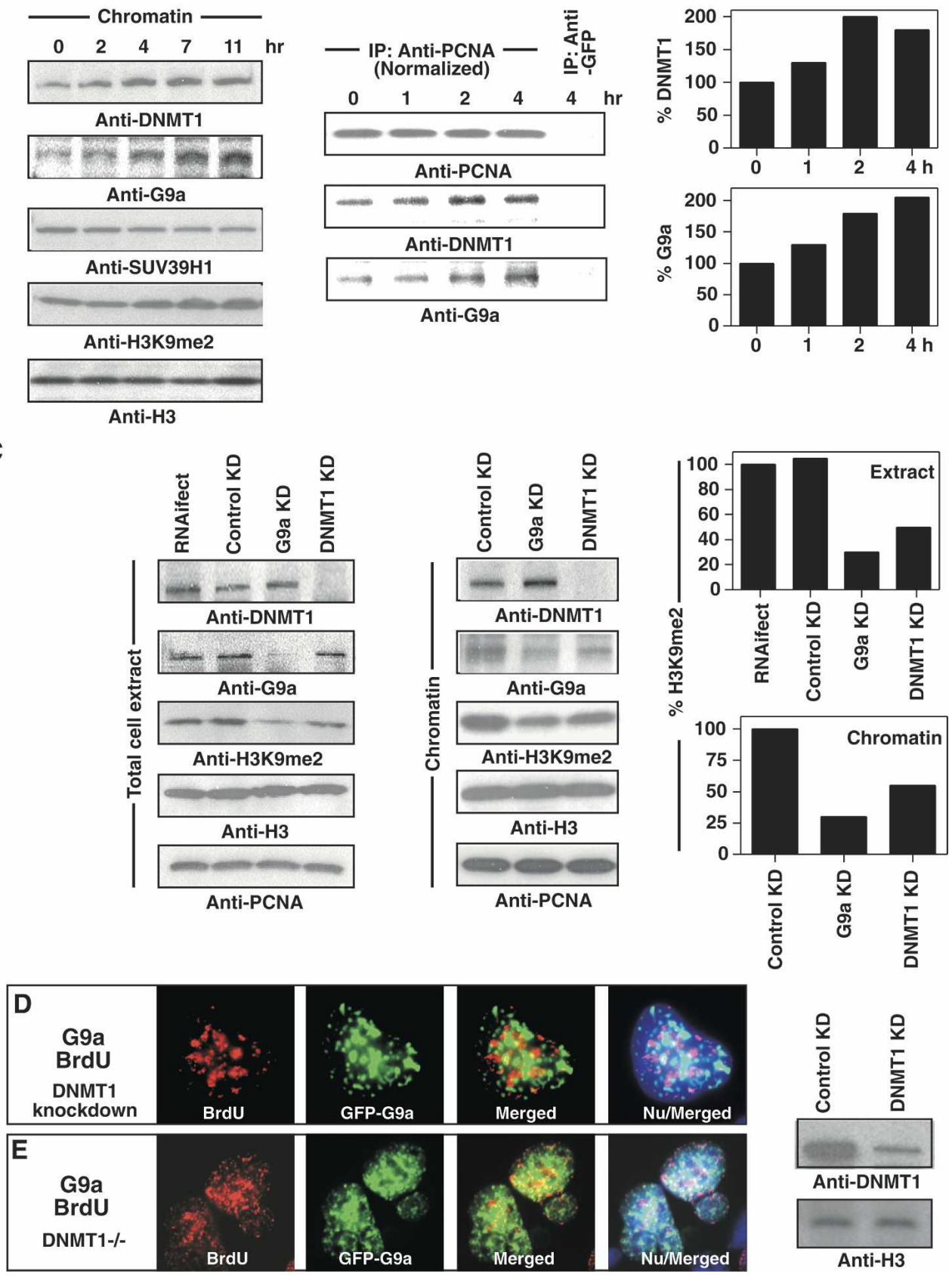

Figure 4. DNMT1 facilitates G9a-mediated methylation of the chromatin. (A) Concurrent DNMT1 and G9a loading onto the chromatin during $\mathrm{S}$ phase. HeLa cells were synchronized by thymidine and aphidicolin and released into regular medium. Time points in hours after the release is indicated at the top with antibody used for Western analysis indicated at the bottom. Chromatin fractions were used in the blot as indicated. (B) Analysis of DNMT1 and G9a recruitment on PCNA during early S phase. Time points in hours after the release is indicated at the top with antibody used for Western analysis at the bottom. Loading for Western analysis is normalized for PCNA to determine DNMT1 and G9a recruitment. (C) DNMT1 knockdown impairs G9a loading and H3K9 methylation. Western blot analysis of the total cell extract (left) and chromatin (right) are shown. The antibodies used are indicated at the bottom and the siRNA-mediated knockdown of DNMT1 (DNMT1 KD) and G9a (G9a KD) are indicated at the top. Control knockdown (Control KD) was performed with siLitmus. (D) Localization profile of G9a and BrdU in DNMT1 knockdown COS-7 cells. BrdU is stained red and GFP-G9a is visualized as green. A portion of knockdown cells was used for Western blot analysis to determine the degree of knockdown for DNMT1 as shown in the right panel. Histone H3 was used as control. (E) Same as in $D$, except that the cells were genetically knockout for DNMT1 in HCT116 background. 
tinguish methylation status of a gene via a pair of methylated or unmethylated gene-specific primers (Herman et al. 1996). If the gene is methylated, only the methylated primer will yield a PCR product. Indeed, IGS-rDNA is methylated and knockdown or depletion of DNMT1 resulted in partial demethylation of IGS-rDNA as a distinct unmethylated gene-specific PCR product was observed (Fig. 5A, lane 1 vs. lane 3). Furthermore, chromatin immunoprecipitation (ChIP) experiments were performed to elucidate whether DNMT1 knockdown will impair G9a loading to IGS-rDNA, thus decreasing local concentration of $\mathrm{H} 3 \mathrm{~K} 9 \mathrm{me} 2$. Indeed, knockdown of DNMT1 severely down-regulated DNMT1 and G9a loading, and decreased $\mathrm{H} 3 \mathrm{~K} 9 \mathrm{me} 2$ concentration, although PCNA loading on IGS-rDNA remained similar (Fig. 5B) as observed before (Fig. 4C). Previously, we have demonstrated that knockdown of G9a by siRNA resulted

A

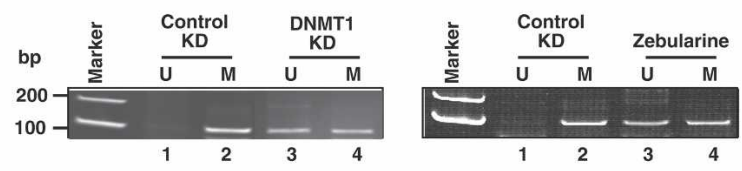

B
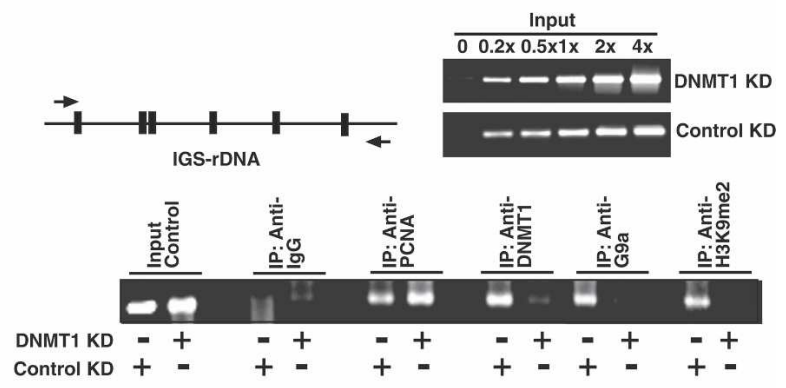

C

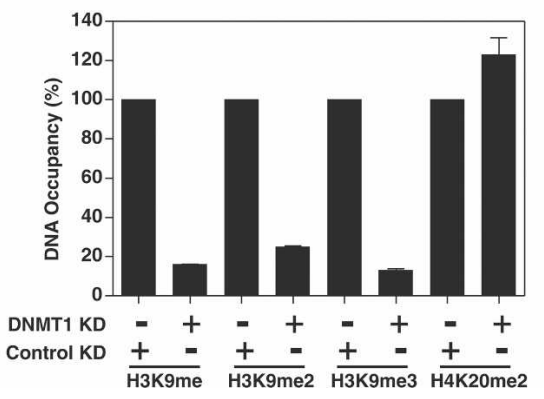

Figure 5. Methylation-specific PCR analysis of IGS-rDNA. (A) In the DNMT1 knockdown genome either by siRNA for DNMT1 (top) or G9a (bottom) and by depleting endogenous DNMT1 with zebularine (right). The expected gene-specific band is $\sim 110$ bp. Unmethylated $(\mathrm{U})$ and methylated $(\mathrm{M})$ genespecific products are shown. (B) ChIP analysis of IGS-rDNA loci. In the top left panel, a line diagram of the 110-bp loci with CpG residues is indicated as vertical filled boxes. The right panel shows the linearity PCR amplification of the knockdown input DNAs. The bottom panel shows the PCR products from the ChIP analysis. The antibodies used for IP are indicated at the top and knockdown conditions are shown at the bottom. $(C)$ Q-PCR analysis of various histone H3 modifications in the IGSrDNA loci. The knockout status is shown at the bottom. in global reduction of di- and trimethylation of $\mathrm{H} 3 \mathrm{~K} 9$ and coexpression of H3 and G9a in Escherichia coli resulted in H3K9me3 formation (Estève et al. 2005b). Biochemical data also suggested that G9a performs mono-, di-, and trimethylation on H3K9 (Patnaik et al. 2004; Collins et al. 2005). Thus, a disruption of G9a loading via DNMT1 knockdown would impair H3K9 methylation. To investigate if chromatin methylation is impaired in IGSrDNA loci, we performed Q-PCR analysis of the ChIP DNA from DNMT1 knockdown and control knockdown cells using $\mathrm{H} 3 \mathrm{~K} 9 \mathrm{me}, \mathrm{H} 3 \mathrm{~K} 9 \mathrm{me} 2, \mathrm{H} 3 \mathrm{~K} 9 \mathrm{me} 3$, and a control H4K20me2-specific antibody to investigate whether chromatin methylation is impaired in IGS-rDNA loci. Indeed, depletion of DNMT1 resulted in reduction of H3K9me, H3K9me2, and H3K9me3, but not for H4K20me2 (Fig. 5C) and H4K20me3 (data not shown). These results suggest that the PCNA-DNMT1 binary complex guides G9a for H3K9 methylation on IGSrDNA loci, and loss of DNMT1 impairs this loading.

G9a and DNMT1 stimulate each other's enzymatic activity

The colocalization of SUV39H1 or G9a with DNMT1 coupled with their direct interactions in pull-down and immunoprecipitation assays suggested two possibilities: that the histone and DNA methylases helped each other bind to the newly replicated chromatin, and that they influenced each other's catalytic activity. If interaction of DNMT1 with G9a or SUV39H1 stimulated its activity via a conformational change, then the effect should be evident on naked DNA templates. Figure 6A shows the results of a DNA methyltransferase activity assay where unmethylated or hemimethylated DNA was incubated with DNMT1 alone or in the presence of SUV39H1 and/ or G9a. Remarkably, both de novo and maintenance DNA methylation, on unmethylated or hemimethylate substrates, respectively, were stimulated only in the presence of G9a. Importantly, a deletion but catalytically active mutant of G9a (delG9a) (Estève et al. 2005b) lacking the N-terminal 633 amino acids (DNMT1-binding region) was unable to activate DNMT1 activity (Fig. 6A). SUV39H1 either alone or with G9a did not affect DNMT1 activity. These data suggest that the association of G9a strongly stimulates DNMT1 activity, implying that the interaction has functional consequences.

Unlike DNMT1, the methylation activity of G9a was only modestly stimulated by full-length DNMT1 ( 25\%) on nucleosomes isolated from HCT116 cells, and this modest stimulation was abolished if a catalytically active deletion mutant of DNMT1 (delDNMT1), lacking the N-terminal 501 amino acids (Pradhan and Estève 2003), was substituted for the full-length DNMT1 in the assay (Fig. 6B). A slightly higher methylation ( 35\%) was observed with nucleosomes assembled in vitro with recombinant histones (data not shown). If G9a stimulate DNMT1 activity, loss of G9a may result in loss of DNA methylation in IGS-rDNA. To examine this hypothesis, MSP assays were performed on G9a knockdown HCT116 genomic DNA. Indeed, a small but significant amount of demethylation was observed (Supplementary Fig. 3a). 
Figure 6. Methylation activation via interaction of DNMT1 and G9a in vitro. (A) DNA methylation activation in the presence of DNMT1 and G9a. A deletion mutant G9a (delG9a) that did not contain the DNMT1binding region was used as control. Components in the in vitro reaction are shown at the bottom. Unmethylated and hemimethylated DNA substrates are shown. The methyl group incorporation in shown at the left. Each reaction was repeated twice. (B) Histone methylation stimulated by DNMT1 on HCT116 nucleosome substrates. Reaction components are indicated at the bottom of the graph. G9a and delG9a were used for methylation reaction. Tritiated methyl group incorporation is in counts per minute at the left. Reactions were repeated twice in duplicates. $(C$, top) G9a recruits DNMT1 onto the nucleosomal array. Prebound G9a on the nucleosomal array is shown at the top along with cofactor AdoMet. DNMT1 concentration was increased as shown at the top along with the antibody used for DNMT1 loading detection shown at right. (Bottom) A similar experiment with delG9a abolished DNMT1 recruitment. (D) DNMT1 catalysis stimulated by G9a in a replication-independent manner. The prebound components used are indicated at the top. The subsequent incubation was carried out with DNMT1 and ${ }^{3} \mathrm{H}$ AdoMet as shown. Fluorography of the methylated DNA is shown at the top and Western blot of G9a loaded onto the chromatin is shown at the bottom with lane numbers.

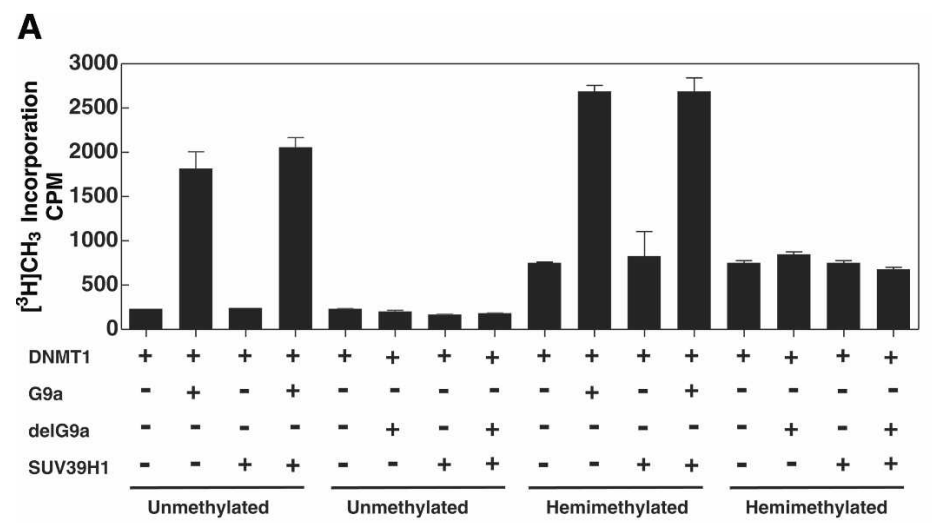

B
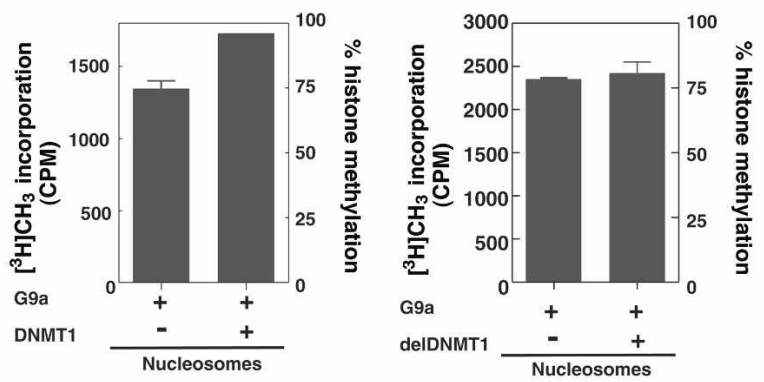

C

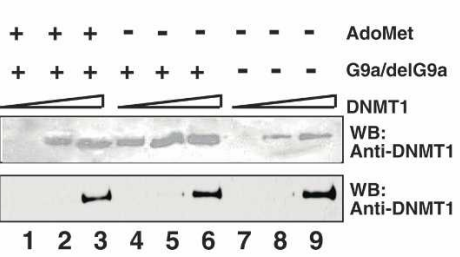

D

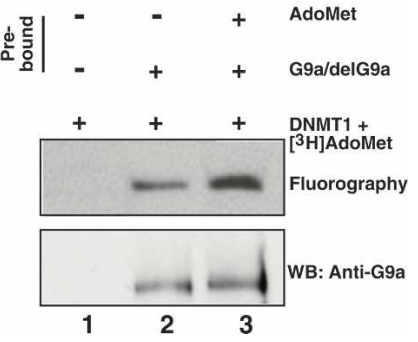

Subsequently, bisulphate sequencing of IGS-rDNA was conducted on DNA derived from control knockdown, 5 AZC-treated, and G9a knockdown cells. In the control knockdown genomic DNA, the CpG site was methylated in all of the clones corresponding to the MSP primer-binding site as compared with $\sim 60 \%$ for G9a knockdown or 5 AZC-treated genomic DNA (Supplementary Fig. 3b). These data suggest that DNMT1 may aid histone methylation catalyzed by G9a on nucleosome substrates during DNA replication (Fig. 2A) and G9a may aid DNMT1 activity on certain loci.

A second prediction of the interaction between G9a and DNMT1 is that it should aid binding of DNMT1 to chromatin substrates. To test this idea, chromatin was assembled using recombinant histones and attached to streptavidin beads. The immobilized chromatin was incubated with G9a or delG9a in the presence and absence of the AdoMet cofactor, washed, and increasing concentrations of DNMT1 were added (Fig. 6C, lanes 1-6). In the absence of prebound G9a, modest levels of DNMT1 were recruited to the chromatin template (Fig. 6C, lanes 7-9). However, in the presence of G9a, a robust recruitment of DNMT1 was observed (Fig. 6C, lanes 1-6, top) and this enhanced recruitment was abolished if delG9a was used (Fig. 6C, lanes 1-6, bottom). We conclude that the interaction between full-length G9a and DNMT1 leads to enhance recruitment of DNMT1 and improved DNA methytransferase activity in vitro, demonstrating the functional significance of the complex. Additionally, the decreased affinity of DNMT1 for chromatin pretreated with G9a and AdoMet (Fig. 6C, lanes 1-3) could be due to rapid turnover of DNMT1 on substrate.

To validate the idea that G9a can stimulate DNA methylation catalyzed by DNMT1 on chromatin in a replication-independent manner, we prebound G9a onto the chromatin array in the presence or absence of cold AdoMet. The prebound chromatin was washed to remove the unbound cold AdoMet and incubated with DNMT1 and ${ }^{3} \mathrm{H}$-AdoMet to determine the effect on DNA methylation in a chromatin context. Following a 1-h incubation, the chromatin arrays were stripped of the histones via proteinase $\mathrm{K}$ treatment and the DNA fragments were phenol/chloroform extracted and ethanol precipitated. DNA methylation was visualized by fluorography of the ${ }^{3} \mathrm{H}$ DNA fragments (Fig. 6D). DNMT1 in isolation methylated DNA poorly, as the ${ }^{3} \mathrm{H}$-methylated 
DNA band was almost invisible after a short exposure (Fig. 6D, lane 1). However, in the presence of prebound G9a without AdoMet, DNA methylation on the chromatin was increased significantly (Fig. 6D, lane 2). The presence of unlabeled AdoMet during prebinding of fulllength G9a enhanced DNMT1 activity severalfold as compared with G9a alone (Fig. 6D, lane 3 vs. lane 2) suggesting either an AdoMet-induced conformational change of G9a facilitated DNMT1 catalysis or that methylated H3K9 stimulated DNMT1 catalysis. To investigate whether G9a remain bound to the chromatin array during the time course of the experiment, especially in the presence of AdoMet, we Western blotted identical sets of experiments and probed the bound G9a with anti-G9a. Indeed, the majority of G9a remained bound to the chromatin in the presence of AdoMet (Fig. 6D, bottom) coinciding with enhanced DNA methylation.

\section{Discussion}

The genome and epigenome are copied at the replication fork. Therefore, events occurring during $S$ phase provide a window of opportunity for eliciting genetic changes or maintaining the existing genetic state. The mechanisms underlying the re-establishment of the epigenetic state are not well understood. Based on our results, DNMT1 binds to G9a and SUV39H1 directly in cells and in vitro. A key question is understanding the precise timing of DNMT1 and G9a recruitment. Our data suggest that the context determines the timing. For example, DNMT1 copurifies with polymerase $(\mathrm{POL} \alpha)$, supporting a model of concomitant DNA replication and maintenance methylation (Vertino et al. 2002). In such a case, the recruitment of DNMT1 may assist G9a. In the current study, we showed that purified chromatin from DNMT1 knockdown cells displayed a significantly reduced amount of G9a loading relative to HeLa wild-type cells, indicating that DNMT1 participates in chromatin loading of G9a. Importantly, the binary complex of DNMT1 and G9a may aid the maintenance DNA methylation process as observed in our in vitro assay. Stimulation of DNMT1 activity is particularly important during DNA replication since biochemical studies suggest that DNMT1 displays low catalytic activity in vitro (Pradhan et al. 1999). Additionally, DNMT1 may reciprocally aid H3K9 methylation by G9a as indicated in our in vitro assays. The colocalization of DNMT1 and G9a by PCNA immunoprecipitation and immunocytochemical analysis places both proteins in close proximity during $S$ phase, validating the biochemical data, suggesting that H3K9 and CpG methylation are concurrent events. However, from the PCNA immunoprecipitation data we cannot conclude that DNMT1-G9a binary complex is directly recruited by PCNA.

The binding of DNMT1, G9a, and SUV39H1 may also follow a sequential path with DNMT1 binding first to form a platform to recruit the histone methylases. Based on the known ability of PCNA to load DNMT1, we propose it would bind first during DNA replication and then recruit G9a or a preformed PCNA-DNMT1-G9a complex. The DNMT1-G9a binary complex is catalytically competent and can perform both histone and DNA methylation. Concurrent with maintenance DNA methylation, H3K9 residues get predominately dimethylated. Either DNMT1 or G9a can be released first from the methylated chromatin. Furthermore, we have demonstrated that DNMT1 interacts directly with G9a and SUV39H1 by coprecipitation from cell extracts and by GST pull-down assays. Detailed analysis of the interaction in vitro on DNA and nucleosomal substrates indicates that the complexes are functional. G9a stimulates DNMT1 activity, while DNMT1 has a modest effect on G9a. Furthermore, knockdown of G9a resulted in DNA methylation impairment on IGS-rDNA loci. An important prediction of such a complex is that one partner should help the other bind chromatin cooperatively. Indeed, prebound G9a significantly stimulates DNMT1 binding to chromatin. Additionally, the complexes colocalize in the cell and at replication foci during $S$ phase and participate in chromatin methylation of IGS-rDNA. A unifying model for these data is presented in Figure 7.

A related hypothesis has been proposed previously with CAF-I (chromatin assembly factor-I), MBD1 (methyl DNA-binding protein 1) and a histone methyltransferase, SETDB1 complex (Sarraf and Stancheva 2004). The trimeric CAF1-MBD1 and SETDB1 complex is associated with histones $\mathrm{H} 3$ and $\mathrm{H} 4$ at $\mathrm{S}$ phase, implying that methylation of $\mathrm{H} 3 \mathrm{~K} 9$ may occur during replication. Immunocytochemical detection of mono-, di-, and trimethylated Lys 9 of histone $\mathrm{H} 3$ using highly specific antibodies demonstrated that $\mathrm{H} 3 \mathrm{~K} 9 \mathrm{mel}$ is distinct at early DNA synthesis, followed by accumulation of H3K9me2 at the nuclear and nucleolar periphery at the mid S phase (Wu et al. 2005). These observations support the presence of G9a during DNA synthesis, since G9a is the predominant enzyme for euchromatic H3K9 methylation. Thus, before the packaging of the chromatin to higher order structures, chromatin modification must occur. Heterochromatin assembly also involves HP1, which binds to H3K9 di- and trimethylated (Jacobs et al. 2004; Wallace and Orr-Weaver 2005). HP1 interacts with p150, the large subunit of CAF-I, suggesting that CAF-I may participate in HP1 redistribution on heterochromatin during replication (Murzina et al. 1999). Furthermore, the presence of G9a-GLP/Eu-HMTase heteromeric complex may aid in H3K9 methylation (Tachibana et al. 2005). However, the precise role of Eu-HMTase in chromatin methylation during cell division is yet to be established. The functional role of other H3K9 methyltransferases, such as Eu-HMT and SETDB1, do not complement with G9a, as genetic deletion of G9a leads to embryonic lethality (Tachibana et al. 2002). It is possible that each histone methyltransferase, such as EuHMTase and G9a, may have different chromatin segments as substrate for methylation that needs further investigation. Thus, the role of chromatin assembly factors, histone modification enzymes, and DNA methyltransferases is to participate in the reinstatement of heterochromatin at the replication fork during $S$ phase via 
Figure 7. Model for chromatin methylation by the DNMT1/G9a complex. $(A)$ During DNA replication, the PCNADNMT1 complex recruits G9a. As the replication fork moves, concurrent events of maintenance DNA methylation of hemimethylated DNA takes place along with G9a-mediated H3K9 dimethylation. Unmethylated and methylated CpGs are shown as open and closed lollypops. Cofactor AdoMet is used as a methyl donor. (B) Post-replicative chromatin methylation involves DNMT1-G9a and DNMT1-SUV39H1 complexes. SUV39H1 can bind to H3K9me2 (blue-filled stars) using its chromodomain and catalyzes $\mathrm{H} 3 \mathrm{~K} 9$ trimethylation. DNMT1 can methylate unmethylated CpG sites. G9a-DNMT1 complexes can bind to H3K9me2 (an intermediate product) with a lower affinity for $\mathrm{H} 3 \mathrm{~K} 9$ trimethylation reaction $(\mathrm{H} 3 \mathrm{~K} 9 \mathrm{me} 3$, filled stars). The presence of G9a in a DNMT1 complex will activate DNMT1 catalysis for additional de novo methylation (methylation spreading) as seen in silenced genes in cancer cells. $(C)$ Methylation-independent gene repression and heterochromatic localization of SUV39H1 and DNMT1. Following post-replicative chromatin methylation, the heterochromatin components of the nucleus are enriched with H3K9me3, which serves as a platform for HP1 binding. HP1 recruits SUV39H1 and DNMT1 for repressor complex formation. DNMT1 is shown to recruit other repressor components such as HDAC1. However, the methylated chromatin may get demethylated to feed into the methylation cycle.

chromatin modification. However, many of these cooperative functions are likely to be required outside $S$ phase for maintenance of heterochromatin. A recent study by Okuwaki and Verreault (2004) demonstrated that DNMT1 is capable of de novo methylation of nucleosomal DNA of 5S rRNA genes. This demonstrates a new capability of DNMT1 outside S phase. Similarly, Easwaran et al. (2004) have demonstrated replication-independent chromatin loading of DNMT1 during G2 and $\mathrm{M}$ phases of mammalian cells to constitutive heterochromatin. This observation has implications in chromatin silencing. The recruitment of G9a to DNMT1 perhaps coordinates histone and DNA methylation long after DNA replication. Furthermore, due to the low catalytic turnover of DNMT1 (Pradhan et al. 1999) stimulation by G9a may aid DNA methylation. This hypothesis is evident in genetic knockout of G9a, resulting in reduction of H3K9 methylation in Prader-Willi syndrome imprinting center and loss of maternal-specific CpG methylation of Prader-Willi syndrome imprinting center in mouse ES cells (Xin et al. 2003). These findings support a possible role for both G9a and DNMT1 in the establishment of histone and DNA methylation.

In summary, we show that two global epigenetic enzymes, DNMT1 and G9a, coordinate synchronized DNA and histone $\mathrm{H} 3 \mathrm{~K} 9$ methylation during DNA replication.

\section{Materials and methods}

Cell culture and constructs

All cell lines (HeLa, HEK 293, Jurkat, and COS-7) were obtained from the American Type Culture Collection (ATCC) and were grown as per recommendations. Parental HCT116 and DNMT knockout cell lines (HCT116 DNMT1 ${ }^{-/}$, Clone 1C1) were grown as described previously (Rhee et al. 2000). Cells were synchronized using double-thimidine block, followed by aphidicolin treatment according to O'keefe et al. (1992).

All GST-DNMT1 constructs have been described previously (Kim et al. 2002), as well as the GST-G9a constructs (Estève et al. 2005b). Details of the fusion constructs of G9a and DNMT1 with GFP or DsRed are available upon request.

\section{Immunoprecipitation, GST pull-down, and Western blot analysis}

Antibody for histone H3 was from Cell Signaling Technology. Anti-DNMT1 and G9a antibodies were from New England Biolabs, and BD Pharmingen, respectively. Antibodies antimonoK9 (\#07-450), anti-dimeK9 (\#07-441; lot: 27271), or -trimeK9 (\#07-442; lot: 24416) of histone H3; anti-dimeK20 (\#07-367) and anti-trimeK20 (\#07-749) of histone H4; PCNA; and antiSUV39H1 were from Upstate Biotechnology. Anti-GFP antibody was purchased from Roche. Nuclear extracts were made as described previously (Andrews and Faller 1991). Coimmunoprecipitation and GST pull-downs were performed as described previously (Kim et al. 2002) except the washes performed with $1 \times$ phosphate-buffered saline (PBS) supplemented with $500 \mathrm{mM}$ $\mathrm{NaCl}$. For activity assays, coimmunoprecipitation was performed in the presence of $50 \mathrm{mM}$ Tris- $\mathrm{Cl}(\mathrm{pH} 7.5)$ and $100 \mathrm{mM}$ $\mathrm{NaCl}$. Densitometric analysis was performed using NIH ImageJ.

Nuclear extracts were prepared from HCT116 wild-type and HCT116 DNMT1 $1^{-/}$colon adenocarcinoma cells (obtained from Dr. Bert Vogelstein, The Johns Hopkins University, Baltimore, $\mathrm{MD}$ ). Immunoprecipitation of the nuclear extract samples were performed using G9a-specific antibody (MBL). The nuclear extracts were prepared from HEK293 cells using IP buffer. Thirty microliters of Protein G/A agarose beads were washed twice 
with IP buffer and equilibrated using the same buffer. Nuclear extract protein equivalent to $1 \mathrm{mg}$ was added to agarose beads $(\mathrm{MBL})$, and then $5 \mu \mathrm{g}$ of antibody specific to G9a was added. Normal mouse IgG (Santa Cruz Biotechnology) was used to immunoprecipitate the same amount of nuclear extract as a negative control. Samples were rotated overnight at $4^{\circ} \mathrm{C}$. Agarose beads were washed three times with $500 \mu \mathrm{L}$ of IP buffer. The protein complex was eluted in $2 \times$ SDS loading buffer $(50 \mu \mathrm{L})$ at $70^{\circ} \mathrm{C}$ for $10 \mathrm{~min}$. The supernatant was collected and analyzed by Western blot using DNMT1 antibody (Novus).

\section{Gel filtration chromatography}

Gel filtration of nuclear extract was performed on HiPrep 26/60 Sephacryl S-200 HR (GE Healthcare Life Sciences) equilibrated in $10 \mathrm{mM}$ Tris (pH. 7.5), $1 \mathrm{mM}$ EDTA, and $500 \mathrm{mM} \mathrm{NaCl}$ using an FPLC apparatus (GE Healthcare Life Sciences). Three milliliters of nuclear extract were loaded $(60 \mathrm{mg})$ onto the column at a flow rate of $0.5 \mathrm{~mL} / \mathrm{min}$ with $3-\mathrm{mL}$ fractions collected. Additional runs using proteins from HMW Gel Filtration Calibration Kit (GE Healthcare Life Sciences) were used to determine the molecular weight of the eluted nuclear extract peaks. Blue dextran was used for determination of the void volume of the column. Ferritin (449 kDa) and aldolase (158 kDa) were used for gel filtration profile monitoring.

\section{DNA and histone methyltransferase assay}

DNMT1, MBP-delG9a (delG9a), and G9a were obtained from New England Biolabs. SUV39H1 was cloned into pVIC1 and purified as described by Chin et al. (2006). DNA methyltransferase assays were carried out at $37^{\circ} \mathrm{C}$ for $30-60 \mathrm{~min}$ in duplicate with a total volume of $25 \mu \mathrm{L}$ of reaction mix as previously described (Pradhan et al. 1999). SNRPN exon 1 duplex DNA (4 $\mu \mathrm{M}$ ) was used for methylation assays with $25 \mathrm{nM}$ DNMT1, $40 \mathrm{nM}$ G9a, $40 \mathrm{nM}$ delG9a (MBP-delG9a), and $40 \mathrm{nM}$ SUV39H1.The reactions were spotted on DE81 (Millipore) membrane and processed as described previously (Pradhan et al. 1999). The histone methyltransferase assay was performed with a synthetic $\mathrm{H} 3$ tail representing the first 17 amino acids along with an N-terminal cys (C-ARTKQTARKSTGGKAPR) as described previously (Patnaik et al. 2004). Following methylation of chromatin by G9a and DNMT1, 2 U of DNase I (New England Biolabs) was used to destroy methylated DNA.

\section{Immunocytochemistry}

COS-7 and HeLa cells were cultured on coverslips and respectively transfected with a mixture of plasmid and FuGENE6 (Roche) or Lipofectamine 2000 (Invitrogen) at a ratio of $3 \mu \mathrm{L} / \mu \mathrm{g}$. The cells were visualized after $48 \mathrm{~h}$ using a Zeiss $200 \mathrm{M}$ microscope with a $63 \times$ oil objective lens at $488 \mathrm{~nm}$ for GFP-DNMT1, GFP-G9a, and GFP-SUV39h1 fusion proteins; $568 \mathrm{~nm}$ for DsRed-DNMT1 and DsRed-G9a detection; and $460 \mathrm{~nm}$ for nuclear staining using Hoechst 33342. For labeling of nascent DNA, cells were incubated for $1 \mathrm{~h}$ with $10 \mu \mathrm{M}$ BrdU before being fixed in $4 \%$ paraformaldehyde and permeabilized with $0.2 \%$ Triton X-100. The DNA was then denaturated with $2 \mathrm{M}$ $\mathrm{HCl}$ for $20 \mathrm{~min}$ and neutralized with $0.1 \mathrm{M}$ sodium borate. After three washes with PBS-Tween $0.1 \%$, BrdU was detected using an anti-BrdU monoclonal antibody conjugated with Alexa Fluor $594 \mathrm{~nm}$ (Molecular Probes). For dimethylated K9 and trimethylated $\mathrm{K} 9$ detection on histone $\mathrm{H} 3$, slides previously blocked by $5 \%$ BSA were incubated overnight at $4^{\circ} \mathrm{C}$ in $1 \%$ BSA PBSTween $0.1 \%$ with anti-dimeK9 or anti-trimeK9 rabbit polyclonal antibodies. After three washes with PBS-Tween 0.1\%, anti-rabbit IgG conjugated with AlexaFluor $594 \mathrm{~nm}$ (Molecular Probes) was added for $1 \mathrm{~h}$ before staining the slides with Hoechst 33342.

\section{Chromatin purification}

HeLa cells were washed twice in PBS (pH 7.4) and scraped in 15 $\mathrm{mL}$ of PBS. After centrifugation $\left(1500 \mathrm{rpm}, 5 \mathrm{~min}\right.$ at $\left.4^{\circ} \mathrm{C}\right)$, the supernatant was discarded and the cells were resuspended in 10 $\mathrm{mL}$ of buffer A (15 mM Tris-Cl at pH 7.5, $5 \mathrm{mM} \mathrm{MgCl}_{2}, 60 \mathrm{mM}$ $\mathrm{KCl}, 0.5 \mathrm{mM}$ DTT, $15 \mathrm{mM} \mathrm{NaCl}, 300 \mathrm{mM}$ sucrose). Ten milliliters of buffer A containing 1\% NP-40 was added and mixed by inverting. After $10 \mathrm{~min}$ on ice, the nuclei was pelleted and resuspended in $5 \mathrm{~mL}$ of ice-cold buffer $\mathrm{A}$. After centrifugation, the pellet was resuspended in buffer $\mathrm{B}(15 \mathrm{mM}$ Tris- $\mathrm{Cl}$ at $\mathrm{pH} 7.5,1$ $\mathrm{mM} \mathrm{CaCl}_{2}, 60 \mathrm{mM} \mathrm{KCl}, 0.5 \mathrm{mM} \mathrm{DTT}, 15 \mathrm{mM} \mathrm{NaCl}, 300 \mathrm{mM}$ sucrose) and $500 \mathrm{U}$ of micrococcal nuclease (Roche) were added for $1.5 \mathrm{~h}$ at $4^{\circ} \mathrm{C}$. The reaction was stopped by adding $50 \mathrm{mM}$ EDTA. The nuclei were pelleted, washed with ice-cold PBS, and then resuspended in $0.5 \mathrm{~mL}$ of buffer C ( $1 \%$ SDS, $10 \mathrm{mM}$ EDTA, $50 \mathrm{mM}$ Tris- $\mathrm{Cl}$ at $\mathrm{pH}$ 8). Thirty micrograms of protein was loaded on SDS-polyacrylamide gels for Western blot analysis. All buffers contained PMSF and protease cocktail inhibitors (Sigma).

\section{Binding and chromatin array recruitment assay}

Chromatin arrays were prepared and biotinylated as described previously (Ikeda et al. 1999). Chromatin was prepared using recombinant Xenopus histones assembled into octamers and bound to arrays by step-wise salt dialysis as described previously (Logie and Peterson 1997; Luger et al. 1999). After salt dialysis, chromatin was immobilized on M280 streptavidin beads (DYNAL) in chromatin-binding buffer $(300 \mathrm{mM} \mathrm{KCl}, 10 \%$ glycerol, 4 mM MgCl 2,1 mM DTT, $200 \mu \mathrm{g} / \mathrm{mL}$ BSA). Immobilized chromatin templates were validated by limited MNase digestion and native PAGE of EcoRI-digested fragments as described previously (Ikeda et al. 1999). G9a was bound to the chromatin array in reaction mix as described above, in the presence or absence of the cofactor AdoMet for $30 \mathrm{~min}$ at room temperature. After washing to remove unbound proteins, the templates were incubated with increasing amounts of DNMT1 at $37^{\circ} \mathrm{C}$ in reaction buffer as previously described above. After washing, the templates were analyzed for DNMT1 recruitment by SDS-PAGE gel electrophoresis and immunoblotting. For fluorography analysis of ${ }^{3} \mathrm{H}$-methylated DNA, the films were exposed at $-80^{\circ} \mathrm{C}$ for $5 \mathrm{~d}$.

\section{Gene knockdown, methylation-sensitive PCR, and ChIP assay}

HeLa cells were transfected twice using RNAiFECT reagent (Qiagen) with $15 \mathrm{nM}$ of siRNA mixes The mixes used were specific for G9a or DNMT1 (New England Biolabs). For control transfection, litmus siRNA was used (New England Biolabs). Seventy-two hours after the second transfection, ChIP or MSP were performed (Estève et al. 2005a). For each IP, $5 \mu \mathrm{g}$ of purified rabbit IgG (Calbiochem), anti-PCNA (Upstate Biotechnology), anti-DNMT1 (New England Biolabs), anti-G9a (Upstate Biotechnology), anti-H3K9me2, anti-H3K9me, anti-H3K9me3, anti-H4K20me2, and anti-H4K20me3 (Upstate Biotechnology) were used. For ChIP assay, DNA was amplified using the following primers: for IGS-rDNA sense, 5'-CCTTCCACGAG AGTGAGAAGC-3', and antisense, 5'-TCGACCTCCCGAA ATCGTACA-3'. The MSP primer sets for IGS-rDNA were unmethylated gene-specific sense, 5'-ATGAGAGTGAGAAGTG 
TGTGTTTGG-3', and antisense, 5'-TCAACCTCCCAAAA TCATACACCAAA-3'; methylated gene-specific sense, 5'-AC GAGAGTGAGAAGCGCGTGTTCGG-3', and antisense, 5'TCGACCTCCCGAAATCGTACACCGAA-3'. 5-aza-2'-deoxycytidine-treated Jurkat genomic DNA was obtained from New England Biolabs. Primer for bisulphate sequencing are available upon request.

For quantitative ChIP assay, IGS-rDNA quantification was performed by real-time PCR, in a Bio-Rad iCycler using iQ SYBR Green Supermix (Bio-Rad). The SYBR green incorporation into double-stranded DNA was measured during each elongation step. Relative values were calculated using actin as an endogenous control. The percentage of DNA remaining upon DNMT1 knockdown was calculated with respect to the mocktreated cells (Litmus siRNA) using the $\Delta \mathrm{Ct}$ method. Primer sets are available upon request. Error bars on the graph represent the standard deviation of triplicates.

\section{Acknowledgments}

We thank B. Vogelstein (The Johns Hopkins University, Baltimore) for the DNMT1-null cell line. We also thank D. Patnaik and M. Pradhan for clones, T. Evans for suggestions, D.G. Comb for encouragement, and New England Biolabs, Inc., for support and assistance. A.R.K. acknowledges research funding from NIH RO1 CA11674.

\section{References}

Andrews, N.C. and Faller, D.V. 1991. A rapid micropreparation technique for extraction of DNA-binding proteins from limiting numbers of mammalian cells. Nucleic Acids Res. 19: 2499.

Cheng, J.C., Yoo, C.B., Weisenberger, D.J., Chuang, J., Wozniak, C., Liang, G., Marquez, V.E., Greer, S., Orntoft, T.F., Thykjaer, T., et al. 2004. Preferential response of cancer cells to zebularine. Cancer Cell 6: 151-158.

Chin, H.G., Patnaik, D., Estève, P.O., Jacobsen, S.E., and Pradhan, S. 2006. Catalytic properties and kinetic mechanism of human recombinant Lys-9 histone H3 methyltransferase SUV39H1: Participation of the chromodomain in enzymatic catalysis. Biochemistry 45: 3272-3284.

Chuang, L.S., Ian, H.I., Koh, T.W., Ng, H.H., Xu, G., and Li, B.F. 1997. Human DNA-(cytosine-5) methyltransferase-PCNA complex as a target for p21WAF1. Science 277: 1996-2000.

Collins, R.E., Tachibana, M., Tamaru, H., Smith, K.M., Jia, D., Zhang, X., Selker, E.U., Shinkai, Y., and Cheng, X. 2005. In vitro and in vivo analyses of a Phe/Tyr switch controlling product specificity of histone lysine methyltransferases. $J$. Biol. Chem. 280: 5563-5570.

Dodge, J.E., Kang, Y.K., Beppu, H., Lei, H., and Li, E. 2004. Histone H3-K9 methyltransferase ESET is essential for early development. Mol. Cell. Biol. 24: 2478-2486.

Easwaran, H.P., Schermelleh, L., Leonhardt, H., and Cardoso, M.C. 2004. Replication-independent chromatin loading of Dnmt1 during G2 and M phases. EMBO Rep. 5: 1181-1186.

Espada, J., Ballestar, E., Fraga, M.F., Villar-Garea, A., Juarranz, A., Stockert, J.C., Robertson, K.D., Fuks, F., and Esteller, M. 2004. Human DNA methyltransferase 1 is required for maintenance of the histone $\mathrm{H} 3$ modification pattern. J. Biol. Chem. 279: 37175-37184.

Estève, P.O., Chin, H.G., and Pradhan, S. 2005a. Human maintenance DNA (cytosine-5)-methyltransferase and p53 modulate expression of p53-repressed promoters. Proc. Natl.
Acad. Sci. 102: 1000-1005.

Estève, P.O., Patnaik, D., Chin, H.G., Benner, J., Teitell, M.A. and Pradhan, S. 2005b. Functional analysis of the $\mathrm{N}$ - and C-terminus of mammalian G9a histone H3 methyltransferase. Nucleic Acids Res. 33: 3211-3223.

Fuks, F., Hurd, P.J., Deplus, R., and Kouzarides, T. 2003. The DNA methyltransferases associate with HP1 and the SUV39H1 histone methyltransferase. Nucleic Acids Res. 31: 2305-2312.

Gilbert, D.M. 2002. Replication timing and transcriptional control: Beyond cause and effect. Curr. Opin. Cell Biol. 14: 377383.

Gruss, C. and Sogo, J.M. 1992. Chromatin replication. Bioessays 14: $1-8$.

Gruss, C., Wu, J., Koller, T., and Sogo, J.M. 1993. Disruption of the nucleosomes at the replication fork. EMBO J. 12: 45334545.

Herman, J.G., Graff, J.R., Myohanen, S., Nelkin, B.D., and Baylin, S.B. 1996. Methylation based PCR: A novel PCR assay for methylation status of CpG islands. Proc. Natl. Acad. Sci. 93: 9821-9826.

Holliday, R. 1994. Epigenetics: An overview. Dev. Genet. 15: 453-457.

Ikeda, K., Steger, D.J., Eberharter, A., and Workman, J.L. 1999. Activation domain-specific and general transcription stimulation by native histone acetyltransferase complexes. Mol. Cell. Biol. 19: 855-863.

Jackson, V. 1990. In vivo studies on the dynamics of histoneDNA interaction: Evidence for nucleosome dissolution during replication and transcription and a low level of dissolution independent of both. Biochemistry 29: 719-731

Jacobs, S.A., Fischle, W., and Khorasanizadeh, S. 2004. Assays for the determination of structure and dynamics of the interaction of the chromodomain with histone peptides. Meth ods Enzymol. 376: 131-148.

Karpf, A.R. and Jones, D.A. 2002. Reactivating the expression of methylation silenced genes in human cancer. Oncogene 21: 5496-5503.

Kim, G.D., Ni, J., Kelesoglu, N., Roberts, R.J., and Pradhan, S. 2002. Co-operation and communication between the human maintenance and de novo DNA (cytosine-5) methyltransferases. EMBO J. 21: 4183-4195.

Lachner, M., O'Sullivan, R.J., and Jenuwein, T. 2003. An epigenetic road map for histone lysine methylation. J. Cell Sci. 116: $2117-2124$

Lehnertz, B., Ueda, Y., Derijck, A.A., Braunschweig, U., PerezBurgos, L., Kubicek, S., Chen, T., Li, E., Jenuwein, T., and Peters, A.H. 2003. Suv39h-mediated histone H3 lysine 9 methylation directs DNA methylation to major satellite repeats at pericentric heterochromatin. Curr. Biol. 13: 11921200.

Leonhardt, H., Page, A.W., Weier, H.U., and Bestor, T.H. 1992. A targeting sequence directs DNA methyltransferase to sites of DNA replication in mammalian nuclei. Cell 71: 865-873.

Li, E., Bestor, T.H., and Jaenisch, R. 1992. Targeted mutation of the DNA methyltransferase gene results in embryonic lethality. Cell 69: 915-926.

Liu, Y., Oakeley, E.J., Sun, L., and Jost, J.P. 1998. Multiple domains are involved in the targeting of the mouse DNA methyltransferase to the DNA replication foci. Nucleic Acids Res. 26: 1038-1045.

Logie, C. and Peterson, C.L. 1997. Catalytic activity of the yeast SWI/SNF complex on reconstituted nucleosome arrays. EMBO J. 16: 6772-6782.

Luger, K., Mader, A.W., Richmond, R.K., Sargent, D.F., and Richmond, T.J. 1997. Crystal structure of the nucleosome 
core particle at $2.8 \AA$ resolution. Nature 389: 251-260.

Luger, K., Rechsteiner, T.J., and Richmond, T.J. 1999. Preparation of nucleosome core particle from recombinant histones. Methods Enzymol. 304: 3-19.

Mosammaparast, N., Ewart, C.S., and Pemberton, L.F. 2002. A role for nucleosome assembly protein 1 in the nuclear transport of histones H2A and H2B. EMBO J. 21: 6527-6538.

Murzina, N., Verreault, A., Laue, E., and Stillman, B. 1999. Heterochromatin dynamics in mouse cells: Interaction between chromatin assembly factor 1 and HP1 proteins. Mol. Cell 4: 529-540.

O'keefe, R.T., Henderson, S.C., and Spector, D.L. 1992. Dynamic organization of DNA replication in mammalian cell nuclei-spatially and temporally defined replication of chromosome-specific $\alpha$-satellite DNA sequences. I. Cell Biol. 116: $1095-1110$.

Okuwaki, M. and Verreault, A. 2004. Maintenance DNA methylation of nucleosome core particles. J. Biol. Chem. 279: 2904-2912.

Patnaik, D., Chin, H.G., Estève, P.O., Benner, J., Jacobsen, S.E., and Pradhan, S. 2004. Substrate specificity and kinetic mechanism of mammalian G9a histone H3 methyltransferase. J. Biol. Chem. 279: 53248-53258.

Peters, A.H., O'Carroll, D., Scherthan, H., Mechtler, K., Sauer, S., Schofer, C., Weipoltshammer, K., Pagani, M., Lachner, M., Kohlmaier, A., et al. 2001. Loss of the Suv39h histone methyltransferases impairs mammalian heterochromatin and genome stability. Cell 107: 323-337.

Peters, A.H., Kubicek, S., Mechtler, K., O'Sullivan, R.J., Derijck, A.A., Perez-Burgos, L., Kohlmaier, A., Opravil, S., Tachibana, M., Shinkai, Y., et al. 2003. Partitioning and plasticity of repressive histone methylation states in mammalian chromatin. Mol. Cell 12: 1577-1589.

Pradhan, S. and Estève, P.O. 2003. Allosteric activator domain of maintenance human DNA (cytosine-5) methyltransferase and its role in methylation spreading. Biochemistry 42: 5321-5332.

Pradhan, S., Bacolla, A., Wells, R.D., and Roberts, R.J. 1999. Recombinant human DNA (cytosine-5) methyltransferase. I. Expression, purification, and comparison of de novo and maintenance methylation. J. Biol. Chem. 274: 33002-33010.

Rea, S., Eisenhaber, F., O'Carroll, D., Strahl, B.D., Sun, Z.W., Schmid, M., Opravil, S., Mechtler, K., Ponting, C.P., Allis, C.D., et al. 2000. Regulation of chromatin structure by sitespecific histone H3 methyltransferases. Nature 406: 593599.

Rhee, I., Jair, K.W., Yen, R.W., Lengauer, C., Herman, J.G., Kinzler, K.W., Vogelstein, B., Baylin, S.B., and Schuebel, K.E. 2000. CpG methylation is maintained in human cancer cells lacking DNMT1. Nature 404: 1003-1007.

Rice, J.C., Briggs, S.D., Ueberheide, B., Barber, C.M., Shabanowitz, J., Hunt, D.F., Shinkai, Y., and Allis, C.D. 2003. Histone methyltransferases direct different degrees of methylation to define distinct chromatin domains. Mol. Cell 12: 1591-1598.

Rountree, M.R., Bachman, K.E., and Baylin, S.B. 2000. DNMT1 binds HDAC2 and a new co-repressor DMAP1 to form a complex at the replication foci. Nat. Genet. 25: 269-277.

Santoro, R. and Grummt, I. 2001. Molecular mechanisms mediating methylation-dependent silencing of ribosomal gene transcription. Mol. Cell 8: 719-725.

Santoro, R., Li, J., and Grummt, I. 2002. The nucleolar remodeling complex NoRC mediates heterochromatin formation and silencing of ribosomal gene transcription. Nat. Genet. 32: 393-396.

Sarraf, S.A. and Stancheva, I. 2004. Methyl-CpG binding protein
MBD1 couples histone $\mathrm{H} 3$ methylation at lysine 9 by SETDB1 to DNA replication and chromatin assembly. Mol. Cell 15: 595-605.

Stillman, B. 2005. Origin recognition and the chromosome cycle. FEBS Lett. 579: 877-884.

Tachibana, M., Sugimoto, K., Nozaki, M., Ueda, J., Ohta, T., Ohki, M., Fukuda, M., Takeda, N., Niida, H., Kato, H., et al. 2002. G9a histone methyltransferase plays a dominant role in euchromatic histone $\mathrm{H} 3$ lysine 9 methylation and is essential for early embryogenesis. Genes \& Dev. 16: 17791791.

Tachibana, M., Ueda, J., Fukuda, M., Takeda, N., Ohta, T., Iwanari, H., Sakihama, T., Kodama, T., Hamakubo, T., and Shinkai, Y. 2005. Histone methyltransferases G9a and GLP form heteromeric complexes and are both crucial for methylation of euchromatin at H3-K9. Genes \& Dev. 19: 815-826.

Taddei, A., Roche, D., Sibarita, J.B., Turner, B.M., and Almouzni, G. 1999. Duplication and maintenance of heterochromatin domains. J. Cell Biol. 147: 1153-1166.

Turner, B.M. 2000. Histone acetylation and an epigenetic code. Bioessays 22: 836-845.

Van Holde, K.E. 1988. Chromatin. Springer Verlag, New York. Vertino, P.M., Sekowski, J.A., Coll, J.M., Applegren, N., Han, S., Hickey, R.J., and Malkas, L.H. 2002. DNMT1 is a component of a multiprotein DNA replication complex. Cell Cycle 1: 416-423.

Vire, E., Brenner, C., Deplus, R., Blanchon, L., Fraga, M., Didelot, C., Morey, L., Van Eynde, A., Bernard, D., Vanderwinden, J.M., et al. 2006. The polycomb group protein EZH2 directly controls DNA methylation. Nature 439: 871-874.

Wallace, J.A. and Orr-Weaver, T.L. 2005. Replication of heterochromatin: Insights into mechanisms of epigenetic inheritance. Chromosoma 12: 1-14.

Wolffe, A.P. 1998. Chromatin structure and function, 3rd ed. Academic Press, San Diego, CA.

Wu, R., Terry, A.V., Singh, P.B., and Gilbert, D.M. 2005. Differential subcellular localization and replication timing of histone H3 lysine 9 methylated states. Mol. Cell. Biol. 16: 2872-2881.

Wysocka, J., Milne, T.A., and Allis, C.D. 2005. Taking LSD1 to a new high. Cell 122: 654-658.

Xin, Z., Tachibana, M., Guggiari, M., Heard, E., Shinkai, Y., and Wagstaff, J. 2003. Role of histone methyltransferase G9a in CpG methylation of the Prader-Willi syndrome imprinting center. J. Biol. Chem. 278: 14996-15000. 


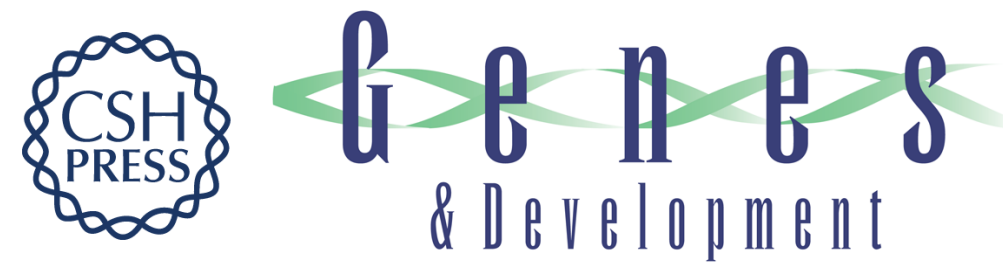

\section{Direct interaction between DNMT1 and G9a coordinates DNA and histone methylation during replication}

Pierre-Olivier Estève, Hang Gyeong Chin, Andrea Smallwood, et al.

Genes Dev. 2006, 20: originally published online November 3, 2006

Access the most recent version at doi:10.1101/gad.1463706

\section{Supplemental http://genesdev.cshlp.org/content/suppl/2006/10/26/gad.1463706.DC1 \\ Material}

References This article cites 56 articles, 19 of which can be accessed free at:

http://genesdev.cshlp.org/content/20/22/3089.full.html\#ref-list-1

License

Email Alerting Receive free email alerts when new articles cite this article - sign up in the box at the top

Service

right corner of the article or click here.

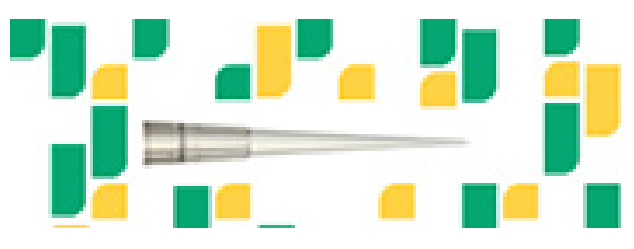

Focused on your science. 